\title{
Correction to: Cascade biocatalysis systems for bioactive naringenin glucosides and quercetin rhamnoside production from sucrose
}

\author{
Samir Bahadur Thapa ${ }^{1} \cdot$ Ramesh Prasad Pandey ${ }^{1,2} \cdot$ Puspalata Bashyal $^{1} \cdot$ Tokutaro Yamaguchi $^{2}$. \\ Jae Kyung Sohng ${ }^{1,2}$ (B)
}

Published online: 22 August 2019

(C) Springer-Verlag GmbH Germany, part of Springer Nature 2019

\section{Correction to: Applied Microbiology and Biotechnology} https://doi.org/10.1007/s00253-019-10060-5

There is an error in the Original Publication of this paper.

The name of the author "Yamaguchi Tokutaro" is incorrect for the first and last name has been interchanged. The correct presentation is "Tokutaro Yamaguchi".

The original article has been corrected.

Publisher's note Springer Nature remains neutral with regard to jurisdictional claims in published maps and institutional affiliations.

The online version of the original article can be found at https://doi.org/ $10.1007 / \mathrm{s} 00253-019-10060-5$

Jae Kyung Sohng

sohng@sunmoon.ac.kr

1 Department of Life Science and Biochemical Engineering, Sun Moon University, 70 Sunmoon-ro 221, Tangjeong-myeon, Asan-si, Chungnam 31460, Korea

2 Department of Pharmaceutical Engineering and Biotechnology, Sun Moon University, 70 Sunmoon-ro 221, Tangjeong-myeon, Asan-si, Chungnam 31460, Korea 